\title{
Exploring $\mathrm{NH}_{3}$ transport properties by tailoring ionic liquids in Pebax-based hybrid membranes
}

Bingbing Yang a,b, Lu Bai a,*, Zhenlei Wang a,d , Haiyan Jiang a,b, Shaojuan Zeng a, Xiaochun Zhang a , Xiangping Zhang a,b,c*

a CAS Key Laboratory of Green Process and Engineering, State Key Laboratory of Multiphase Complex Systems, Beijing Key Laboratory of Ionic Liquids Clean Process, Institute of Process Engineering, Chinese Academy of Sciences, Beijing 100190, China.

b School of Chemical Engineering, University of Chinese Academy of Sciences, Beijing 100049, China.

${ }^{c}$ Zhengzhou Institute of Emerging Industrial Technology, Zhengzhou 450000, China

d School of Chemistry and Chemical Engineering, Qingdao University, Qingdao 266071, Shandong, China

*Correspondence and requests for materials should be addressed to lbai1207@ipe.ac.cn; xpzhang@ipe.ac.cn 


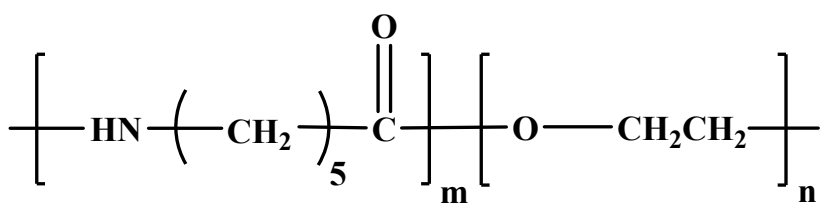

Figure S1. Chemical structure of Pebax ${ }^{\circledR}$ MH 1657. 


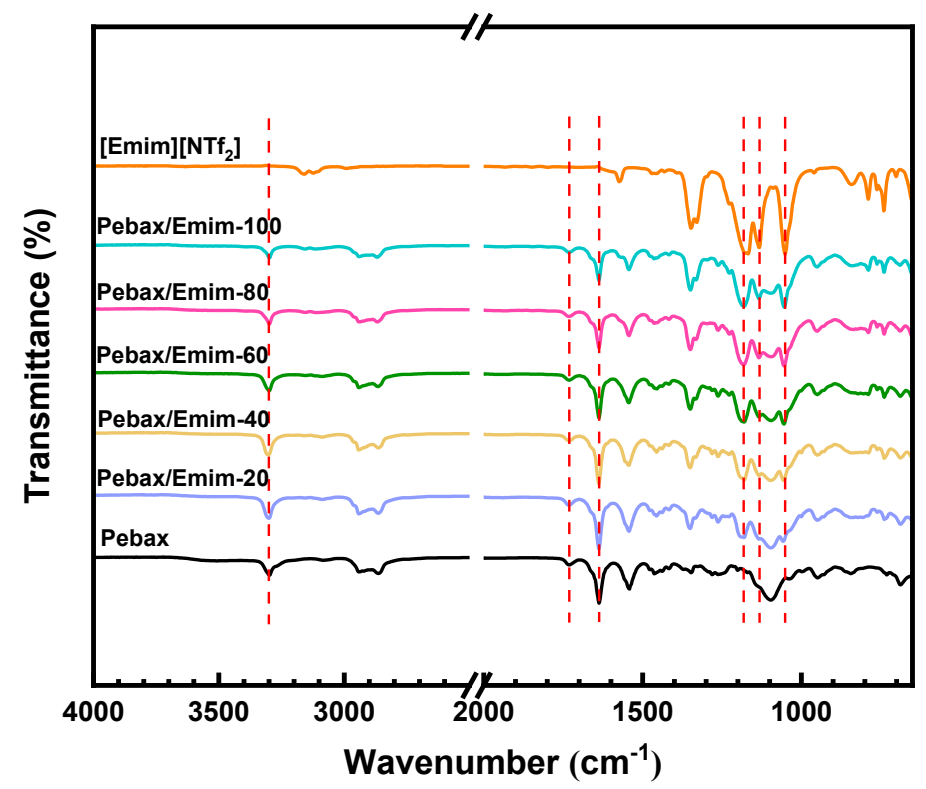

Figure S2. FTIR spectra of Pebax/[Emim][NTf $]$ membranes, the neat Pebax membrane, and $[$ Emim $]\left[\mathrm{NTf}_{2}\right]$. 

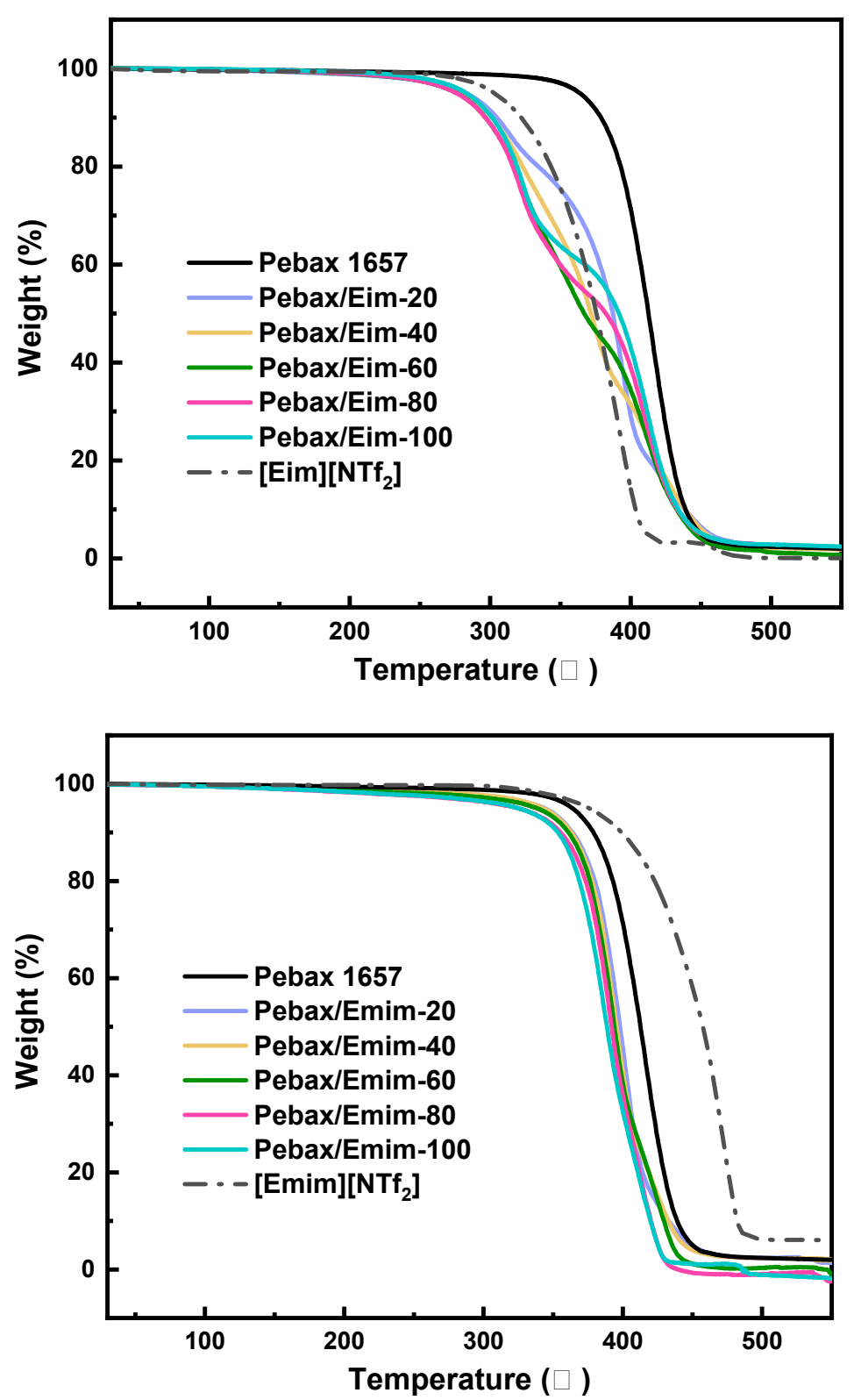

Figure S3. TGA of Pebax/[Eim] $\left[\mathrm{NTf}_{2}\right]$ membranes and Pebax/[Emim] $\left[\mathrm{NTf}_{2}\right]$ membranes. 
Table S1. Thermal properties of Pebax/[Eim] $\left[\mathrm{NTf}_{2}\right]$ membranes, the neat Pebax membrane, and $[$ Eim $]\left[\mathrm{NTf}_{2}\right]$ characterized by DSC.

\begin{tabular}{cccccccc}
\hline \multirow{2}{*}{ Membrane } & $\mathrm{T}_{\mathrm{g}}\left({ }^{\circ} \mathrm{C}\right)$ & \multicolumn{2}{c}{$\mathrm{T}_{\mathrm{m}}\left({ }^{\circ} \mathrm{C}\right)$} & & \multicolumn{3}{c}{$\mathrm{X}_{\mathrm{C}}(\%)$} \\
\cline { 3 - 4 } & & PEO & PA & & PEO & PA & total \\
\hline Pebax & -48.5 & 16 & 201.5 & & 14.8 & 12.8 & 14.0 \\
Pebax/Eim-20 & -49.7 & 7.5 & 187.7 & & 1.9 & 9.9 & 5.1 \\
Pebax/Eim-40 & -50.9 & - & 179.3 & & - & 6.7 & 2.7 \\
Pebax/Eim-60 & -51.1 & - & 174.9 & & - & 5.1 & 2.0 \\
Pebax/Eim-80 & -52.3 & - & 163.9 & & - & 2.8 & 1.1 \\
Pebax/Eim-100 & -54.3 & - & 144.6 & & - & 2.3 & 0.9 \\
{$[$ Eim][NTf $]$} & -82.1 & - & - & & - & - & - \\
\hline
\end{tabular}

\section{Note:}

The degree of crystallinity for the membranes were calculated the following equation:

$$
X_{C}=\frac{\Delta H_{m}}{\Delta H^{0}} \times 100
$$

$\Delta \mathrm{H}_{\mathrm{m}}$ is the melting enthalpy of PEO or PA segment, and $\Delta \mathrm{H}^{0}$ is the melting enthalpy when the polymer is $100 \%$ crystalline, which is $166.4 \mathrm{~J} / \mathrm{g}$ in the case of PEO and 230 $\mathrm{J} / \mathrm{g}$ in the case of PA. ${ }^{1}$ The total crystallinity was calculated by considering $60 \%$ PEO and $40 \%$ PA. 


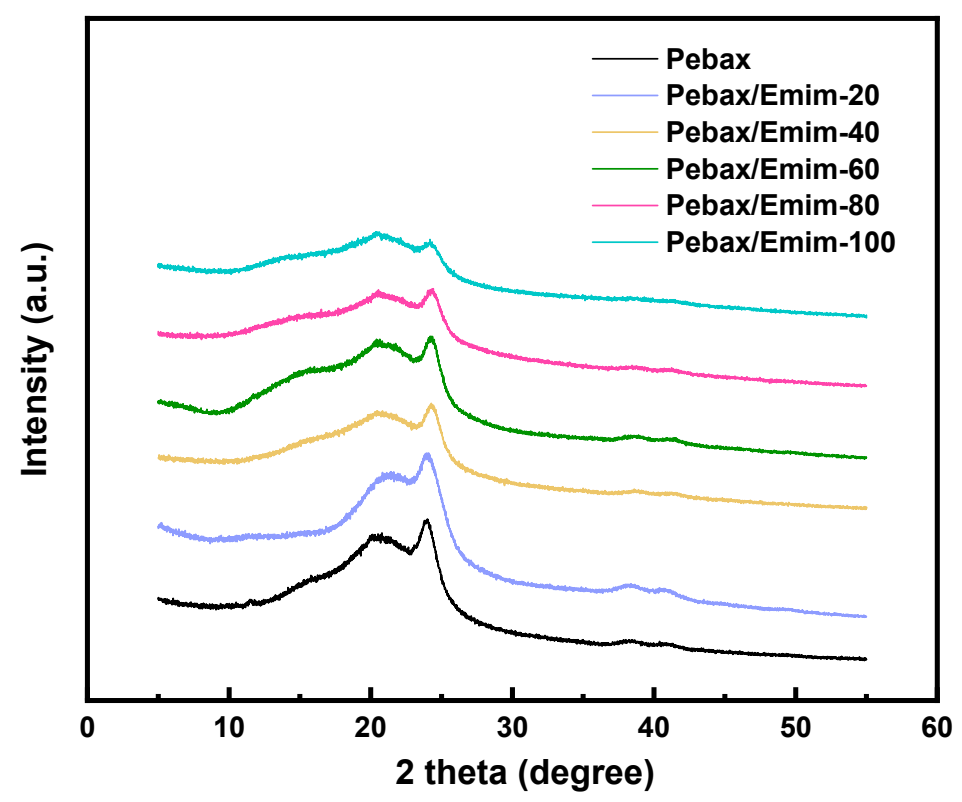

Figure S4. XRD analysis of Pebax/[Emim] $\left[\mathrm{NTf}_{2}\right]$ membranes. 

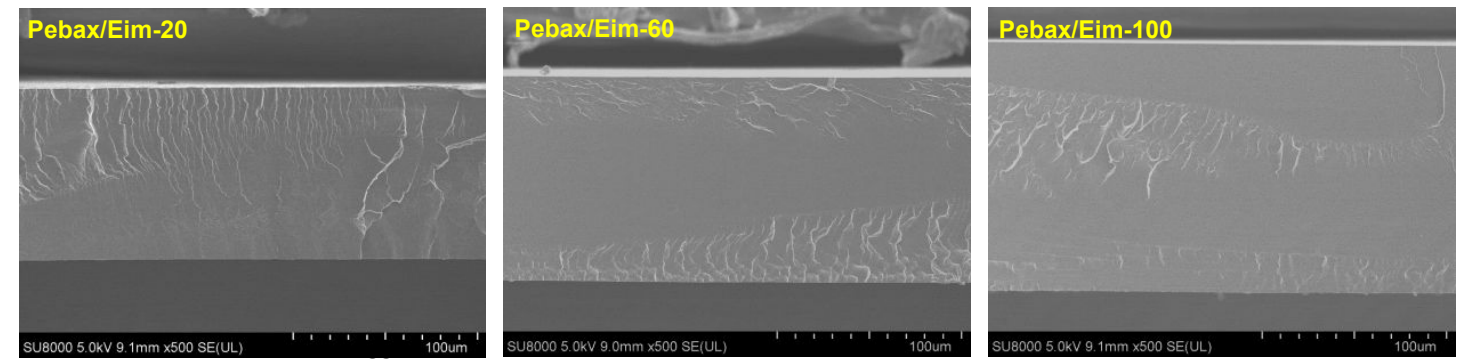

Figure S5. Cross-sectional SEM images of Pebax/Eim-20, Pebax/Eim-60, and Pebax/Eim-100 from top to the bottom. 


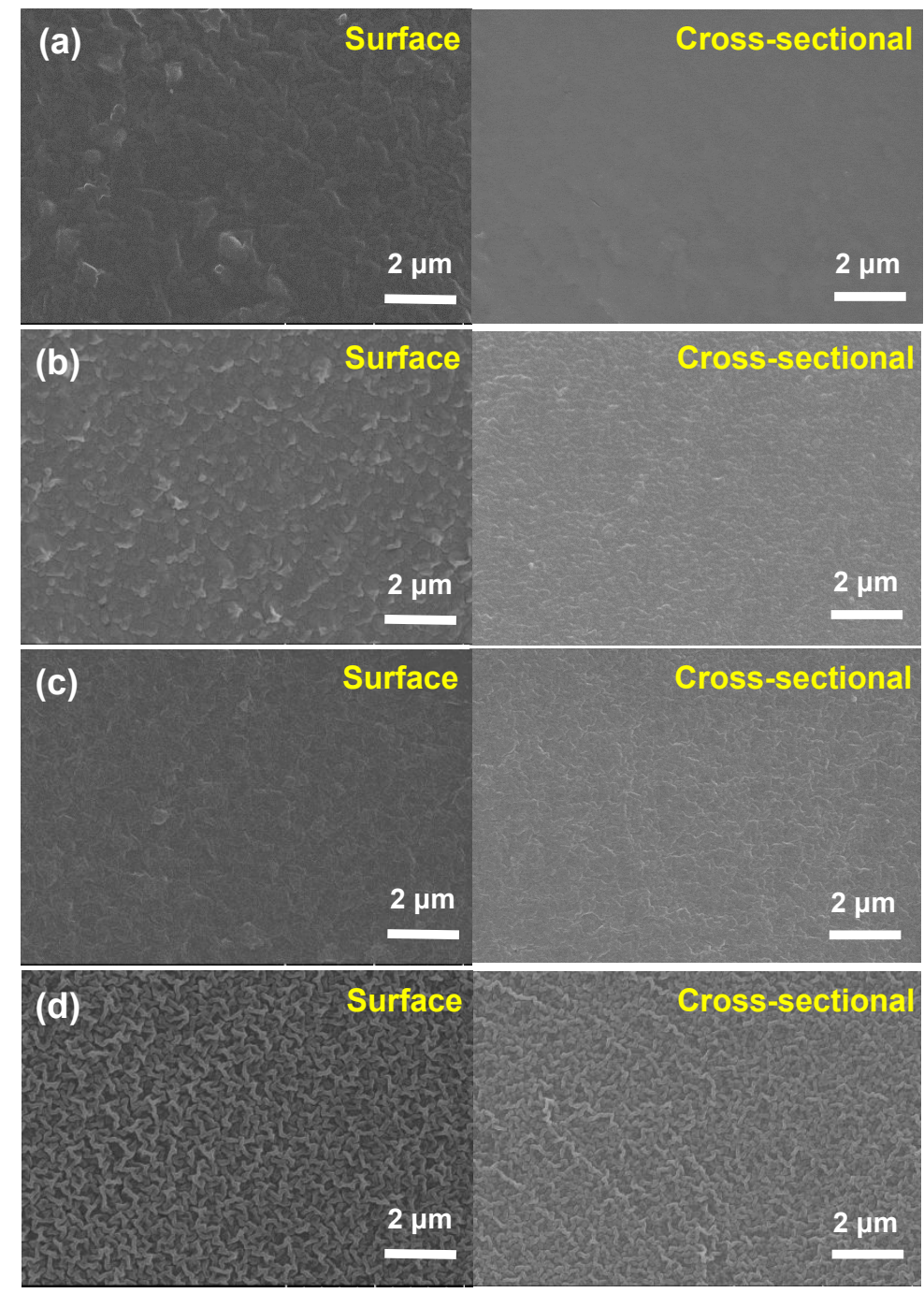

Figure S6. Surface and cross-sectional SEM image of Pebax/[Emim] $\left[\mathrm{NTf}_{2}\right]$ membranes and the neat Pebax membrane. (a) the neat Pebax membrane, (b) Pebax/Emim-20 membrane, (c) Pebax/Emim-60 membrane, (d) Pebax/Emim-100 membrane. 
(a)
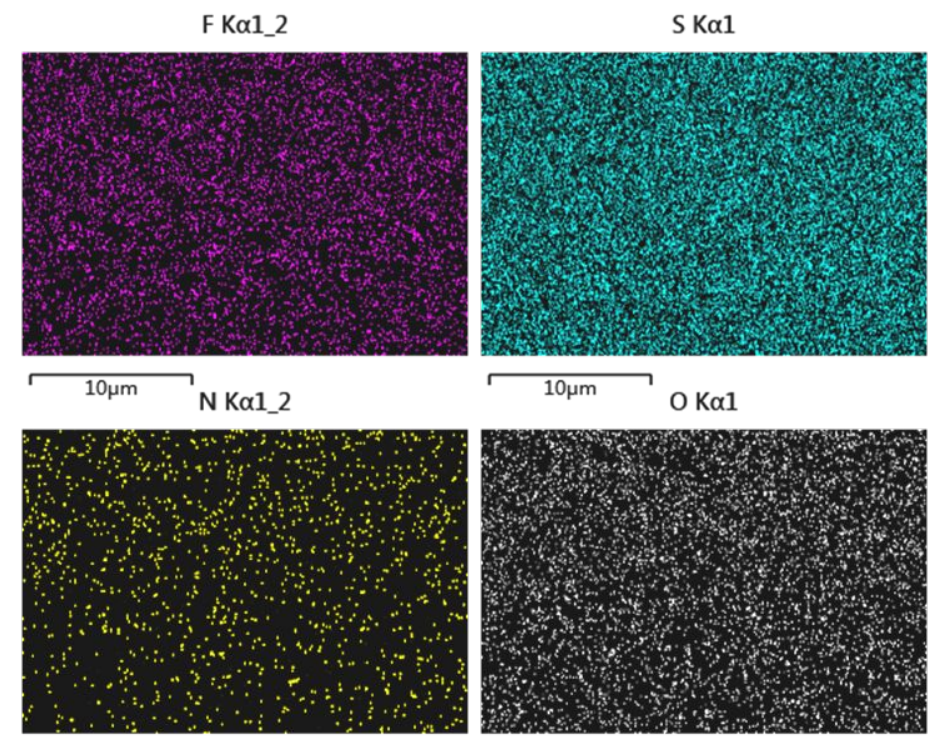

(b)

F K $1 \_2$

$\mathrm{SK} \alpha 1$
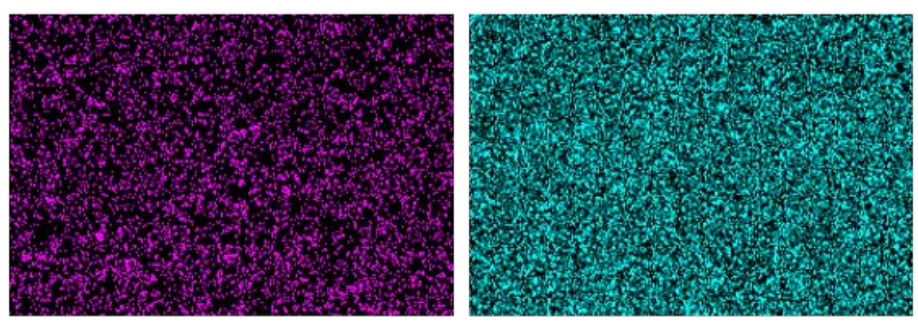

$\overbrace{10 \mu \mathrm{m}}$ N Ko1_2

$10 \mu \mathrm{m}$ O Ka1

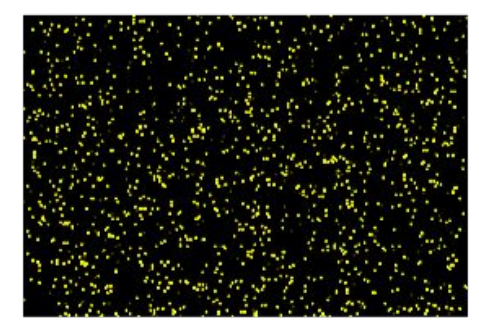

$10 \mu \mathrm{m}$

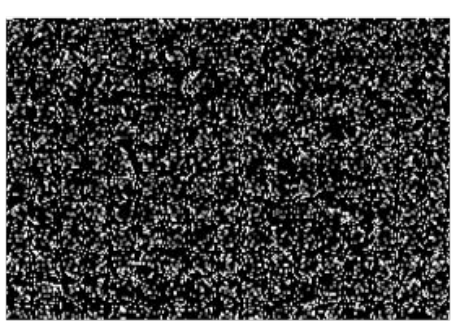

$10 \mu \mathrm{m}$

Figure S7. Elements distribution mapping of (a) Pebax/Eim-100 membrane and (b)

Pebax/Emim-100 membrane. 


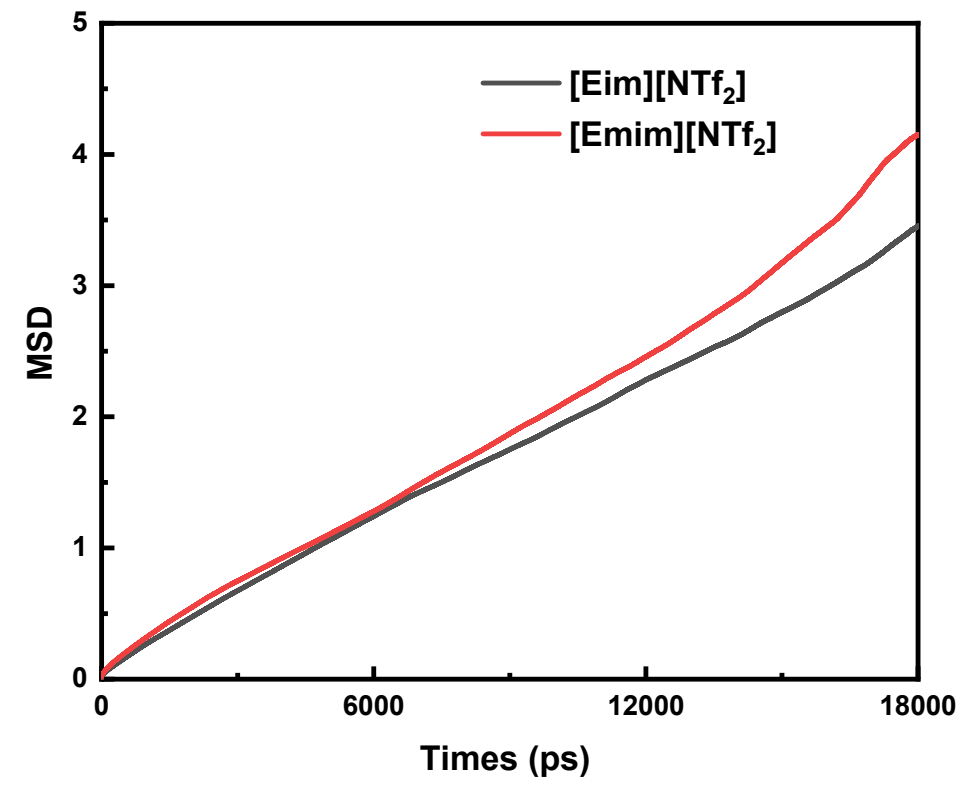

Figure S8. MSD plot at $298 \mathrm{~K}$ and 1 bar for $\mathrm{NH}_{3}$-[Eim] $\left[\mathrm{NTf}_{2}\right]$ and $\mathrm{NH}_{3}-\left[\right.$ Emim] $\left[\mathrm{NTf}_{2}\right]$.

Table S2. Self-diffusion coefficients of $\mathrm{NH}_{3}$-IL system.

\begin{tabular}{ccc}
\hline & $\mathrm{NH}_{3}-[$ Eim $]\left[\mathrm{NTf}_{2}\right]$ & $\mathrm{NH}_{3}-\left[\right.$ Emim $\left._{[}\right]\left[\mathrm{NTf}_{2}\right]$ \\
\hline $\mathrm{D}\left(\times 10^{-11} \mathrm{~m}^{2} / \mathrm{s}\right)$ & 2.97 & 3.56 \\
\hline
\end{tabular}




\section{Reference}

1. Sanaeepur, H.; Ahmadi, R.; Ebadi Amooghin, A.; Ghanbari, D., A novel ternary mixed matrix membrane containing glycerol-modified poly(ether-block-amide) (Pebax 1657)/copper nanoparticles for $\mathrm{CO}_{2}$ separation. J. Membr. Sci. 2019, 573, 234-246. 